M. Lacroix, a geologist, represented the Institut de France; and M. Caullery, a zoologist, acted on behalf of the French delegates.

\section{Loss of the Dana}

Ix is reported in The Times of June 24 that the Danish Government's scientific research ship Dana sank on June 23 in the North Sea, sixty miles west of Ringkjöbing, Jutland, after a collision with a German trawler. The director of the vessel's scientific work, Dr. A. V. Tåning, and the crew were saved. The Dana was well known to men of science and others through the work of the late Prof. Johannes Schmidt, director of the Physiological Department of the Carlsberg Laboratory, Copenhagen, on the migration of eels. It may be remembered that the oceanographical expedition of the Dana in 1928-30 was described in an article by Prof. Johannes Schmidt in NATURE of March 21, 1931, p. 444 and March 28, p. 487 , which included a reproduction of a photograph of the Dana.

\section{Floodlighting for the Royal Silver Jubilee}

THe floodlighting of London and of many provincial cities has generally been favourably received by the public. The use of coloured light for buildings like the London County Hall and Hampton Court Palace has been severely criticised. The latter development was partly due to the invention of gaseous electric lamps which provide an economical method of producing coloured lights. In the Illuminating Engineer of June, P. Good reviews the Royal Jubilee electric lighting. He points out that the floodlighting of a building produces a visual impression which is quite unrelated to the daylight picture and should be so judged. If it has produced a satisfactory impression, it can be justified on artistic grounds. The Horse Guards Parade, illuminated by white light in 1931, was illuminated by violet light in 1935. Although one paper described it at the Jubilee as "a magic castle of palest violet", yet to most people it looked like a temporary structure of plaster and not worthy to be compared with its appearance on the earlier occasion when illuminated by white light. The electrical industry has shouldered the burden of the cost of providing permanent installations at Buckingham Palace, the Horse Guards Parade, the National Gallery and 'Big Ben'. Other interests are paying the cost of the permanent floodlighting of St. Paul's Cathedral. The floodlighting of public gardens has been universally praised. St. James's Park at night illuminated by 300 gas floodlights was a great attraction. When the development of the buildings on the south side of the Thames is completed, it is to be hoped that arrangement will be made for floodlighting and that commercial advertisements will be exeluded.

\section{Electric Supply Tariffs in Great Britain}

A serious hindrance to the rapid development of public electric supply in Great Britain is the great inequality in the charges made for electricity in many neighbouring districts. In a paper on public supply tariffs by J. A. Sumner read to the Institution of Electrical Engineers on February 28, it is concluded, after a careful study of methods of lowering the costs of distribution, that it is not unreasonable to forecast that electricity will be available within the next few years to all consumers at a rate of $0 \cdot 5 d$. per unit. Mr. Sumner begins by comparing the costs per kilowatt of a private supply station with that of a public supply. Statistics for the case when Diesel engines are used for the private supply prove that it is the more expensive. It appears that many undertakings are selling electricity for power purposes at a lower rate than is required to compete with the real costs of running private plant. Hence in some cases the domestic consumer is penalised unfairly. It is pointed out that the distinction between 'urban' and 'rural' supply is sometimes unnecessary, as in many cases the capital expenditure for dwellings near the mains is much the same in the two cases. The analysis of the statistics proves that the merging of electricity areas into much larger single districts than at present is necessary for the reasonable standardisation of tariffs. It is possible in this way to balance the inevitable deficit of a newly-developed area against the surplus from the older areas. By this means a uniform tariff can be kept throughout each single large administrative district.

\section{Applications of Photo-electric Control}

THE G.E.C. Journal (General Electric Company) of February gives an interesting review of electrical progress and development in 1934. Many useful devices are described. Aerodrome obstruction and boundary lights must be switched on when daylight is poor and when darkness approaches in the evening. It is essential that the pilots see the boundary of the aerodrome and any obstructions in the vicinity. The photo-cell has been successfully applied to the control of these lights. At Croydon Airport the switching on of the obstruction light is controlled by a photocell amplifier. Another useful application of photocells is to control the speed of escalators. The wear and tear of escalators like those in the underground railways of London which are in continuous use is extremely heavy; and renewals and repairs are expensive and, owing to the restricted space, are difficult to carry out. It is desirable to keep the speed low during slack periods at the less-frequented stations when no one is on the escalator. At the entrance to the stairway, a suitable lamp is installed to shine across the footway on to a photo-cell similarly mounted on the other side, just below the handrail. When this beam is interrupted by the entrance of a passenger, the stairway is speeded up in several stages so that the passenger feels no shock, and the escalator continues to run at a high speed until the passenger has time to reach the top. This is attained by a time delay device using a radio valve. If other passengers come on to the stairway before the last one reaches the top, the time delay device resets, so that the high speed continues until the last passenger gets to the top, after which the low speed comes into operation. 